\title{
White blood cell activation in Raynaud's phenomenon of systemic sclerosis and vibration induced white finger syndrome
}

\author{
C S Lau, A O'Dowd, J J F Belch
}

\begin{abstract}
Systemic sclerosis (SSc) and vibration induced white finger syndrome (VWF) are common causes of secondary Raynaud's phenomenon. Previous studies have suggested an increase in inflammation in patients with SSc. Vibration induced white finger syndrome occurs in workers exposed to vibration and is now a prescribed disease. In VWF, although it is recognised that vibration can cause direct damage to blood vessels, it does not explain why only some workers are affected. It is possible that an inflammatory process develops in these patients in the same way as is seen in SSc. Leukotriene $B_{4}$, produced mainly by polymorphonuclear cells, is a potent mediator of inflammation. The plasma thiol concentration shows the degree of oxidation of plasma and a decreased concentration indicates the increased production of free radicals which are capable of oxidative damage.
\end{abstract}

In this work, the white blood cell (WBC) production of leukotriene $B_{4}$ and plasma thiol concentrations were measured in patients with SSc and VWF. Fifty nine patients were studied: 34 had SSc and 25 had VWF. The results were compared with 25 matched normal controls and are expressed as the median and range. After stimulation of the polymorphonuclear cells with calcium ionophore A23187 $(1 \mu \mathrm{g} / \mathrm{ml})$, patients with SSc and VWF were found to have significantly increased leukotriene $B_{4}$ production (23.5 $(14.4-44.0)$ and $26(14.4-39.4) \mathrm{ng} / 10^{6}$ cells, respectively) compared with normal controls $\left(17 \cdot 2(6 \cdot 0-38 \cdot 0) \mathrm{ng} / 10^{6}\right.$ cells $)$. The plasma thiol concentration was shown to be significantly lower in patients with SSc and VWF (445 $(375-475)$ and $450(417-510) \mu \mathrm{mol} / 1$, respectively) compared with normal controls (480 (418-555) $\mu \mathrm{mol} / \mathrm{l})$.

Our results show increased leukotriene $B_{4}$ production and increased free radical activity in patients with SSc and VWF. Although previous indirect evidence has suggested increased WBC activity in patients with SSc, this is reported directly here for the first time. In addition, the possibility of an inflammatory process occurring in patients with VWF, as shown here, has not previously been studied. This may be a further mechanism to explain the poor circulation in the fingers of these patients.

Systemic sclerosis ( $\mathrm{SSc}$ ) is a chronic condition with variable disease expression. Despite its heterogeneity, however, secondary Raynaud's phenomenon and vascular endothelial cell damage are common features. ${ }^{12}$ Previous studies have shown an increase in basal chemiluminescence, reflecting the release of free radicals from white blood cells (WBCs), in patients with SSc and have suggested this may be one of the mechanisms of vascular damage in these patients. ${ }^{3}$ In patients with vibration induced white finger syndrome (VWF), a known cause of secondary Raynaud's phenomenon which occurs in workers exposed to vibration, the pathophysiology is not yet fully known. ${ }^{4}$ It is recognised that vibration can cause direct damage to blood vessels. However, direct trauma does not explain why only some workers are affected and we wondered if white blood cell (WBC) activation also occurs in these patients.

Research into vascular diseases has shown an important role for WBCs. ${ }^{5}$ Activated WBCs may cause the obstruction of blood flow in patients with secondary Raynaud's phenomenon who already have a tendency to vasospasm. WBCs can physically obstruct the circulation by aggregating to each other and adhering to the vascular wall. They can also reduce the blood flow via the release of active chemicals. Two such mechanisms are the generation of leukotriene $\mathbf{B}_{4}$ and free radicals.

The aim of this study was to investigate changes in the level of leukotriene $B_{4}$ and free radical activities in patients with SSc and VWF and to compare the results with those obtained from matched controls.

\section{Patients and methods}

Thirty four patients with secondary Raynaud's phenomenon associated with SSc and 25 patients with VWF were studied. All the patients with VWF were, or had been, employed as boilermakers exposed to vibrating machines such as chippers, grinders, and buffs. All had grade III VWF as described by Taylor and Brammer. ${ }^{4}$ The results were compared with 25 age, sex, and smoking matched workers not exposed to vibration. As SSc is predominantly a disease of women and VWF a disease of men, these two groups could not be matched for sex. The table shows the clinical details of these patients.

None of the subjects had taken any drugs known to interfere with the tests and all gave informed consent for the study. Smokers were asked to refrain from smoking from midnight prior to the day of testing. Blood was sampled using a standard technique at the same time of day. 
Clinical data and comparison of patients with systemic sclerosis $(S S c)$ and vibration white finger syndrome (VWF) with control subjects

\begin{tabular}{llll}
\hline $\begin{array}{l}\text { Patient } \\
\text { characteristics }\end{array}$ & $\begin{array}{l}\text { Patients with } \\
S S c(n=34)\end{array}$ & $\begin{array}{l}\text { Patients with } \\
V W F(n=25)\end{array}$ & $\begin{array}{l}\text { Controls } \\
(n=25)\end{array}$ \\
\hline $\begin{array}{l}\text { Median (range) } \\
\text { age (years) }\end{array}$ & 43 & 49 & 44 \\
$\begin{array}{l}\text { Male:female } \\
\text { No of smokers }\end{array}$ & $5: 29$ & $(27-68)$ & $(25-63)$ \\
$\begin{array}{l}\text { Median (range) } \\
\text { duration of } \\
\text { symptoms (years) }\end{array}$ & 9 & $25: 0$ & $25: 0$ \\
$\begin{array}{c}\text { Median (range) } \\
\text { duration of }\end{array}$ & - & 5 & 19 \\
$\begin{array}{l}\text { vibration exposure } \\
\text { (years) }\end{array}$ & & $(3-20)$ & - \\
& & 29 & \\
\end{tabular}

\section{LEUKOTRIENE $B_{4}$}

A $10 \mathrm{ml}$ volume of venous blood was anticoagulated with sodium heparin, which was then mixed by inversion with $5 \mathrm{ml}$ of $6 \%$ dextran 70. Leucocyte rich plasma was removed after gravity sedimentation. This was then centrifuged and mononuclear cells and any remaining media were removed. Red cells were lysed by double strength saline and the polymorphonuclear cells were separated after further centrifugation. The polymorphonuclear cells were then stimulated with calcium ionophore A23187 ( $1 \mu \mathrm{g} / \mathrm{ml})$. After five minutes, the incubation was terminated by centrifugation at $12000 \mathrm{~g}$ for 30 seconds in an Eppendorf centrifuge. The resultant supernatant was aspirated and stored for subsequent determination of leukotriene $B_{4}$ by radioimmunoassay. $^{6}$

\section{PLASMA THIOLS}

Concentrations of thiol in plasma were estimated as a measure of free radical activity and are a measure of albumin thiol, the sulphydryl groups of which are oxidised to disulphides by the action of free radicals. ${ }^{7}$ Thus a decrease in plasma thiol is a measure of increased free radical activity. The plasma thiol concentration was measured by photometric analysis using the technique first described by Ellman. ${ }^{8}$ As this

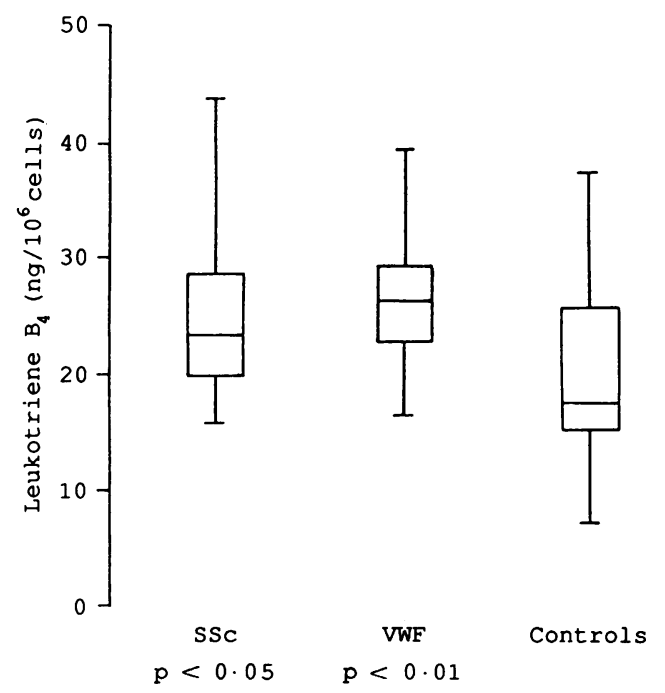

Figure 1 Leukotriene $B_{4}$ concentrations in patients with systemic sclerosis $(S S c)$ and vibration induced white finger syndrome $(V W F)$ compared with controls. Results given are median and range; interquartile range is boxed.

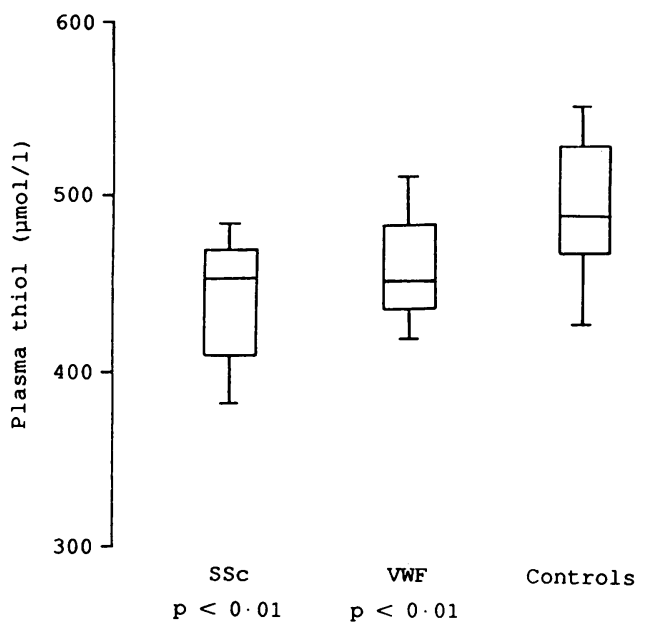

Figure 2 Plasma thiol levels in patients with systemic sclerosis $(S S c)$ and vibration induced white finger syndrome $(V W F)$ compared with controls. Results given are median and range; interquartile range is boxed.

assay was a later development, only 15 patients with SSc, 12 patients with VWF, and 16 controls were studied in this way.

\section{Results}

Figures 1 and 2 show the results obtained as the median and range. Statistical calculations were performed with the Mann-Whitney U test.

The production of leukotriene $\mathrm{B}_{4}$ from stimulated polymorphonuclear cells was increased in patients with SSc $(23.5(14.4-44 \cdot 0)$ $\mathrm{ng} / 10^{6}$ cells; $\left.\mathrm{p}<0.05\right)$ and VWF $(26(14 \cdot 4-39 \cdot 4)$ $\mathrm{ng} / 10^{6}$ cells; $\left.\mathrm{p}<0.01\right)$ compared with the controls $\left(17 \cdot 2(6 \cdot 0-38 \cdot 0) \mathrm{ng} / 10^{6}\right.$ cells).

The plasma thiol concentration was lower in patients with SSc $(445(375-475) \mu \mathrm{mol} / \mathrm{l})$ and VWF (450 (417-510) $\mu \mathrm{mol} / \mathrm{l})$ compared with controls $(480(418-555) \mu \mathrm{mol} / \mathrm{l})(\mathrm{p}<0.01$ in the two groups).

\section{Discussion}

In this study it has been shown for the first time that there is an increase in leukotriene $B_{4}$ production from the polymorphonuclear cells of patients with SSc. Previous work suggesting increased free radical activity in this disorder has been confirmed. We have also shown a similar increase in leukotriene $B_{4}$ production and free radical activity in patients with VWF, suggesting that increased WBC activity also occurs in this disease. As SSc predominantly affects women and VWF predominantly affects men, it was not possible to match the two patient groups and the control group for sex. However, previous work has shown no sex variation in leukotriene $B_{4}$ production, as measured by radioimmunoassay in normal subjects. ${ }^{9}$ Previous stadies have also shown plasma thiol concentrations to be independent of sex in normal subjects and in patients with rheumatoid arthritis. ${ }^{10}$ We recently studied 74 normal healthy subjects ( 38 men and 36 women; age and smoking habit matched) and found no sex variation in their plasma thiol concentrations (men: 472 (336-561) $\mu \mathrm{mol} / \mathrm{l}$; women: 461 
(358-534) $\mu \mathrm{mol} / \mathrm{l}$, median (range)) (unpublished data). Thus, it is valid to make a direct comparison of the leukotriene $\mathrm{B}_{4}$ and plasma thiol concentrations within the three subject groups (SSc, VWF, and control) studied here.

Vibration induced white finger syndrome is a condition which affects a large proportion of the workforce exposed to vibrating tools and is of such severity that since 1985 it has been a prescribed disease eligible for compensation. ${ }^{11}$ As yet there is no known cure and the full pathophysiology is not known. It has been shown that vibration can damage the blood vessel wall. ${ }^{12}$ Repeated ischaemic attacks following vibration exposure produce anatomical changes in the blood vessel walls ${ }^{13}$ with media hypertrophy at a later stage. Despite this extensive pathology seen in the late stages of VWF, the initial cause of the hyperactivity of these arteries remains unknown.

Up to $99 \%$ of patients with SSc have vasospastic symptoms and in some patients these may precede the development of other features of the disease. ${ }^{1}$ Previous studies have suggested a link between vascular endothelial cell damage and Raynaud's phenomenon in SSc, ${ }^{14} 15$ although the cause or consequence of this relation is not clear. The mechanism of vascular damage in SSc is not yet fully understood. ${ }^{16}$ Previous studies have suggested a contributory role of the polymorphonuclear cells-for example, there is increased chemotactic and phagocytotic activity in patients with SSc. ${ }^{17}$

Leukotrienes are biologically active derivatives of arachidonic acid. They are formed by the 5-lipoxygenase enzyme ${ }^{18}$ and have been shown to be potent mediators of inflammation. Polymorphonuclear cells are the major source of leukotrienes. Leukotriene $\mathrm{B}_{4}$ has been shown to be a potent chemotactic and aggregating agent and polymorphonuclear cells move towards and accumulate at sites of injury or infection in response to leukotriene $B_{4}$. The adhesion of polymorphonuclear cells to the endothelial lining of blood vessels has also been shown to be mediated by leukotriene $B_{4}$. Not only is leukotriene $B_{4}$ important in inflammation, but it may also contribute to thrombosis. As the production of leukotriene $\mathrm{B}_{4}$ is increased, WBCs become activated. WBCs are less deformable than red cells and may promote microcirculatory malperfusion in the low flow state. ${ }^{19}$ Activated WBCs are considerably harder and may also aggregate to form clumps which may impede the circulation..$^{20}$ An increase in the adhesion of polymorphonuclear cells to the endothelial lining of blood vessels may also be a contributory factor. Activated WBCs have also been implicated in vessel wall damage, which may interact with other polymorphonuclear cells to activate the coagulation system and cause platelet aggregation. Thus, an increase in leukotriene $B_{4}$ production in patients with SSc and VWF could be relevant in the development of Raynaud's phenomenon and vascular occlusion in these patients.

In addition to the release of lysosomal enzymes, activated WBCs also release other noxious products such as free radicals. Previous studies have shown an increase in basal chemi- luminescence $^{3}$ and enhanced oxidative metabolism of polymorphonuclear cells. ${ }^{21}$ These substances are toxic because they initiate the chain reaction of lipid peroxidation. Free radicals are also pre-thrombotic ${ }^{22}$ via their ability to damage the endothelium and by selectively increasing the production of the platelet aggregant thromboxane $A_{2}$. As short lived species they are difficult to measure directly. However, plasma thiol concentrations (mainly albumin thiols) show the degree of oxidation of the plasma. Albumin conformation is altered by free radical generation and therefore the plasma thiol concentration is a good measure of free radical activity. ${ }^{723}$ Although plasma thiols exist mainly as part of the plasma albumin in molecules, their concentrations are not dependent on the plasma albumin concentration and changes in plasma thiol concentrations seem to reflect the number of available thiol groups per albumin molecule rather than changes in albumin concentration. ${ }^{24}$ These two patient groups have normal albumin concentrations. In addition, none of the subjects studied had taken any drugs known to alter the plasma thiol concentrations. Thus, the decreased concentrations of plasma thiol seen in patients with SSc and VWF reflect increased oxidative metabolism and free radical production. The increase in free radical and leukotriene $B_{4}$ production may have a synergistic effect as studies have shown the former to enhance the chemotactant properties of the latter. ${ }^{25}$

Our results suggest that the poor circulation in the fingers in Raynaud's phenomenon may be partly mediated through the activation of WBCs. It is likely, however, that these changes are not a primary event but develop later. In patients with VWF, the initial effect of vibration in the digital vasculature is to stimulate proliferation of the medial coat and, later, the intima of the arterial wall. Although this is rarely severe enough to cause arterial occlusion in the fingers, the abnormal vessel wall will activate WBCs as they flow past. Damage to the blood vessel wall is also a feature of SSc. White blood cells enhance oxidative stress with a subsequent increase in free radical activity and further tissue damage. This enables a vicious cycle to be set up of ischaemia and reperfusion, vessel damage, WBC activation then further ischaemia.

\section{Conclusions}

We have confirmed the increased free radical generation occurring in patients with $\mathrm{SSc}$, and have shown an increase in leukotriene $B_{4}$ production from polymorphonuclear cells of patients with SSc. We have also shown that leukotriene $\mathrm{B}_{4}$ production and free radical activity are increased in patients with VWF. Previous work has concentrated on delineating abnormalities of the vessel wall and has failed to explain the intermittent nature of the symptoms. In association with severe vessel spasm, alterations in the rheology and release of WBCs could explain the episodic nature of these symptoms and contribute to our understanding of the pathophysiology of this condition, which is 
becoming a common and important occupational problem.

J J F B and C S L are supported by grants from the Raynaud's Association and the Oliver Bird Fund Foundation. We thank Dr $M$ Chopra for her contribution towards the assay of plasma thiol.

1 Akesson A, Wollheim F A. Organ manifestation in 100 patients with progressive systemic sclerosis: a comparison between the CREST syndrome and diffuse scleroderma. $\mathrm{Br}$ I Rheumatol 1989; 28: 281-6.

2 Jayson $M \mathrm{I} \mathrm{V}$. The microcirculation in systemic sclerosis. Clin Exp Rheumatol 1984; 2: 85-91.

3 Czirjak L, Danko K, Sipka S, Zeher M, Szegedi Gy. Polymorphonuclear neutrophil function in systemic sclerosis. Ann Rheum Dis 1987; 26: 113-7.

4 Taylor W, Brammer A J. Vibration effects on the hand and arm in industry: an introduction and review. In: Brammer A J, Taylor W, eds. Vibration effects on the hand and arm in A J, Taylor W, eds. Vibration effects on the

5 Belch J J F. The white blood cell-a new cardiovascular risk factor? In: Shepherd J, ed. Coronary risk factor revisited. Amsterdam: Elsevier, 1989: 51-5.

6 Salmon J A, Simmons P M, Palmer R M J. A radioimmunoassay for leukotriene $B_{4}$. Prostaglandins 1982; 23: 225-35.

7 Del Maestro R F. An approach to free radicals in medicine and biology. Acta Physiol Scand 1980; 492 (suppl): 153-68.

8 Ellman G E. Tissue sulphydryl groups. Arch Biochem Biophys 1959; 82: 70-7.

9 O'Dowd A. Metabolites of arachidonic acid and their role in inflammatory disease [PhD thesis]. Glasgow: Univ of Glasgow, 1991 .

10 Schoen R, Hauss W H, Ott V R, Boni A, Gunther R, Steffen C. Serum sulfhydryl groups in rheumatoid arthritis. $Z$ Rheumatol 1977; 36: 73-6.

11 Taylor $\mathrm{W}$. Vibration white finger: a newly prescribed disease. BMf 1985; 291: 921.

12 Pykko I. A physiological study of the vasoconstrictive reflex in traumatic vasospastic disease. Work and Envirommental Health 1974; 11: 170-86.
13 Ashes W F, Cook W T, Old J W. Raynaud's phenomenon of occupational origin. Arch Environ Health 1962; 5: 333-43. 4 Kahaleh M B Osborne I, LeRoy E C. Increased factor VIII/von Willebrand factor antigen and von Willebrand factor activity in scleroderma and Raynaud's phenomenon. Ann Intern Med 1981; 94: 482-4.

15 Belch J J F, Zoma A A, Richards I M, McLaughlin K, Forbes C D, Sturrock R D. Vascular damage and Factor Forbes $C \mathrm{D}$, Sturrock $\mathrm{R} \mathrm{D}$. Vascular damage and Factor Int 1987; 7: 107-11.

16 LeRoy E C, Smith E M, Kahaleh M B, Trojanowska M,

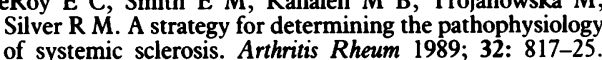
of systemic sclerosis. Arthritis Rheum 1989; 32: 817-25.

17 Spisani S, Dovigo L, Colamussi V. Leukocyte migration and phagocytosis in progressive syste

18 Smith $M \mathrm{~J} \mathrm{H}$. Biological activities of leukotriene $\mathrm{B}_{4}$ (Isomer III). In: Sammuelsson B, Paoletti R, eds. Advances in prostaglandin, thromboxane and leukotriene research, 9 . New York: Raven Press, 1982: 283-92.

19 Bagge U, Branemark P-I, Slalak R. Measurement and influence of white cell deformability. In: Lowe G D O Barbenel J C, Forbes C D, eds. Clinical aspects of blood viscosity and cell deformability. Berlin: Springer Verlag, 1981: $27-36$.

20 Fisher T C, Belch J J F, Barbenel J C, Fisher A C. Human whole-blood granulocyte aggregation in vitro. Clin $S_{C i}$ 1989; 76: 183-7.

21 Maslen C, Woolf A D, Hall N D, Maddison P J. Enhanced oxidative metabolism of neutrophils from patients with systemic sclerosis. Br 7 Rheumatol 1987; 26: 113-7.

22 Belch J J F, Chopra M, Hutchison S, Lorimer R, Sturrock $R$ D, Forbes $C D$. Free radical pathology in chronic arterial diseases. Free Radic Biol 1989; 6: 375-8.

23 Banford J C, Brown D H, Hazelton R A, McNeil C J, Smith W E, Sturrock R D. Altered thiol status in patients with rheumatoid arthritis. Rheumatol Int 1982; 2: 107-11.

24 Pullar T, Zoma A, Capell H A, Khan M F, Brown D H Smith W E. Alteration of thiol and superoxide dismutase Smith $\mathrm{W}$. Alteration of thiol and superoxide dismutase status in rheumatoid arthritis treat

25 Chopra M, Belch J J F, Smith W E. A comparison of the free radical scavenging activity of leukotrienes and prostaglandins. Free Radic Res Commun 1988; 5: 95-9. 